\title{
Currency Exposure and Time Scales: Application of Wavelet Method to Malaysian Non-financial Firms
}

\author{
Wan Nurhanan Wan Suhaimi, Hishamuddin Abdul Wahab, Rabihah Md. Sum
}

\begin{abstract}
The paper estimates the multiscale relationship between stock prices and exchange rates of 75 Malaysian non-financial firms by applying the wavelet analysis on daily data running from 1995 to 2016. The analysis is done for the overall sample and also by segregating the selected firms into 15 industries in Malaysia. Results from the ordinary least square (OLS) regression are also obtained for comparison purpose. The beta coefficients of exposure are shown to exhibit multiscale tendency in all analyses. Higher exposure is recorded at higher timescale for the overall and negative exposure, confirming the initial prediction of higher exposure in wider investment horizon. The study also shows higher wavelet exposure at high scale compared to the exposure obtained from the OLS estimate, providing support on the higher measurement power of the wavelet analysis to study the exposure level.
\end{abstract}

Index Terms: Exchange rate, Currency exposure, Wavelet, Malaysia.

\section{INTRODUCTION}

Uncertainty of foreign exchange market was primarily highlighted after the collapse of the Bretton Woods system in 1973. Over the years, currency exposure which arises from foreign trading activities has been a key concept in modern finance. [1], [2] and [3] defined the exposure as the changes in stock returns and firm values resulted by changes in exchange rate. The interaction between the return levels and the conditions of the currency market showcases an important role in facilitating the overall economy. Another finding suggests lower currency exposure in advance foreign exchange market compared to developing market [4]. The different levels are due to the numerous strategies and tools undertaken to alleviate the impact of the unexpected exposure in developed market.

In line with the theoretical and practical importance of foreign currency exposure, numerous methodological adjustments have been made to increase the power of the exposure measurement model [2], [5], [6]. This is in parallel with the assertion [7] of the potential methodological weaknesses and data limitation on the existing empirical test. Stemming from the total exposure model by [1], the residual

Revised Manuscript Received on November 11, 2019.

* Correspondence Author

Wan Nurhanan Wan Suhaimi, Academic Fellow at the Faculty of Science and Technology (FST), Universiti Sains Islam Malaysia.

Hishamuddin Abdul Wahab, PhD, Faculty of Science and Technology (FST), Universiti Sains Islam Malaysia.

Dr. Rabihah Md., PhD, Faculty of Science and Technology (FST), Universiti Sains Islam Malaysia. model later included the market index [5], [8]. The model is widely used to measure the level of currency exposure across numerous markets, with further modifications to include a few factors such as asymmetric exposure [2], [9] and time-variation [6]. However, absence of appropriate methodology has hindered past researchers from succinctly measure the exposure with respect to varying time-scales in order to accommodate the vast investors' preferences. The varying investment horizons among the investors shapes for unique linkage between stock market and foreign exchange market across different frequencies [10]. Together with the recent development in the methodological field, better measurement on the currency exposure across different time-scale has become feasible and viable. So far, no study has been conducted to measure multiscale currency exposure in developing market despite the relatively higher exchange rate exposure in the market. Malaysia as a developing country with robust trading activities provides a relevant sample study due to its exposure to the currencies fluctuations. However, [3] highlighted the scarcity of prominent studies on Malaysian market, aside from the studies by [4] and [11] that focused on Malaysia market. In addition, the study also goes deeper by analysing the multiscale exposure from the industry level. Following the precaution taken by [6], focusing on an industry will enable clear distinction of the exposure level based on the specific industry characteristics and practices. Addressing the endogeneity will provide more robust results on the level of multiscale exposure between the industries in Malaysia.

This study aims to measure the level of currency exposure across different time scales using the wavelet multiscale measurement for Malaysian non-financial firms. The purpose is to investigate whether the 75 selected Malaysian firms showcase multiscale nature. This study argues that the analysis on multiscale currency exposure in Malaysia will enhance the understanding and knowledge on the level currency exposure in the country. Evidence of multihorizon nature of currency exposure will enable numerous parties to implement more comprehensive investment strategies. This study also paves way for future studies on the potential of multiscale nature to increase the power of the exposure measurement model. Originality of the study lies on the evidence of multiscale nature of currency exposure by focusing on a developing country that is robustly involved with trading activities. 
The study provides evidence of multiscale exposure among Malaysian sample non-financial firms towards currency fluctuations between 1995-2016. We estimate the beta exposure using decomposed daily returns under 7 timescales. The study also provides that high exposure is concentrated at the high frequency data through the industry analysis. The following sections of the study are organised as follow: Section 2 reviews the literature on the currency exposure and the applicability of wavelet transformation. Section 3 provides a brief introduction on the Malaysian stock market and all the data involved in the study. The section continues with a discussion on the Wavelet and regression techniques. Section 4 discusses the results and Section 5 concludes the findings.

\section{LITERATURE REVIEW}

The effect of currency fluctuations towards the investment return had been vastly studied. While the majority of the studies tried to increase the power of their measurement, the studies only managed to show a somewhat low level of exposure. Study by [7] increased their measurement power by incorporating event-study method to analyse the daily stock return of the US firms towards the declines in Mexican peso and Thai baht. Findings by [12] supported the relevancy of event study method as the study found prevalent impact of foreign currency derivative during the Asian financial crisis. However, [7] still found low exposure level despite their methodological approach. Another mainstream approach was the incorporation of the asymmetric exposure into the exposure model [13], [14], [15], [16]. Investigation on the asymmetric exposure supported the connotation that further in-depth analysis on the exposure would provide different and more detailed findings. This was shown by [16] whose study showed 40 percent of significant asymmetric exposure. Still, there was no definite consensus on the superior measurements or adjustments over the others [17].

Sensitivity to exposure level is due to the non-proportionate return interval between the security and the market. According to [18], increment in return interval prompted higher beta value for high-risk securities, while lower beta values were recorded for low-risk securities. As the study also associated the high-risk securities with small firms and low-risk securities with big firms, the beta values across the scales were also bound to the risk nature of the securities and the magnitude of the operating firms. Likewise findings were found by [19] for Australian firms. In other words, the relationship between the stock return and exchange rates dynamically changed throughout different scales and frequencies. In this regard, the conventional time-domain approach needed to include other frequencies forms in order to sufficiently cater the varying time scales nature of the financial market traders [10]. This was illustrated by [10] who showed the ordinary least square (OLS) estimation in their study only provided results that were similar to the findings from the $5^{\text {th }}$ quantile median function rather than encompassing the overall findings. [18] also failed to provide any evidence of beta sensitivity to lengthened return interval. The inability to capture the effect of the longer return interval might be due to the loss of a lot of information about the beta dynamics across different intervals [17]. This gap highlighted the practicality of the wavelet through its ability to decompose data for different timescales without losing any information. Since the base scales already included any non-stationary components, the data also did not require to be differenced or detrended [17].

Wavelet analysis was considered as an enhancement of the traditional Fourier transforms. However, wavelet analysis expanded the functions trough translation and dilation of the fixed function known as mother wavelet. In the analysis, Haar and Daubechies mother wavelets are considered as superior measurements for financial time series as they were capable to capture the economic and financial time series characteristics [20]. In addition to its multiscale property, the localisation of wavelet in time and frequency also permitted closer connection between the function and their respective coefficients. These characteristics enabled wavelet to possess two methodological benefits which were the flexibility to handle very irregular data series and ability to isolate the contaminated noise in the data [21], [20], [22]. Consideration of the timescale aspect was crucial as economic and financial variables simultaneously operated on varying timescales and their relationship may differ across these timescales [18]. Delayed adjustment to any new information and infrequent trading were also regarded as the reasons leading to the multiscale bias. These conditions would lead to autocorrelation problem in the stock returns and eventually prompted biased beta estimation [23]. This was further stressed by [24] in which the beta tended to be sensitive towards different timescales due to different frequencies of the beta for macroeconomic risks. Henceforth, numerous studies had used the wavelet analysis to test various economic and financial aspects such as the linear and non-linear Granger causality between spot and future oil prices [25], systematic risk beta at different time scales [17], intraday seasonality extraction that is free of model selection parameters [26], property of foreign exchange volatility [27], time and scale dependencies of intraday Asian currency spot exchange rate [28], and orthogonal decomposition of some economic variables by time scales [29]. More recent findings by [30] showed the existence of multiscale exposure among four currencies in Ghana, in which the stronger co-movements were found during shorter period and reflected the potential of contagion effect among the currencies. However, this study is the first to conduct an analysis on the Malaysian market with special attention on the exchange rate exposure. 


\section{METHODOLOGIES}

\section{A. SAMPLE SELECTION AND DATASET}

Daily data on stock return, currency exchange (MYR/USD) and market index were collected from Bloomberg. The initial sample consists of 1,000 firms listed on the Bursa Malaysia. The data are then filtered to consist firms with daily stock return from 1995 to 2016 , leaving 207 firms in the sample. In order to enable better data collection, the final sample comprises 75 firms across 15 industries with 5 biggest firms are selected for each industry. The industries are the travel and leisure, industrial engineering and transportation, food and beverages producers, oil and gas producers and equipment, general industrials, construction and materials, industrial metals and mining, chemicals, automobile and parts, general retailer, household goods and construction, technology hardware, software, equipment and services, forestry and paper, personal and leisure goods, and electronic and electrical equipment industries. We follow [2] to exclude financial firms because most of them are also market makers in foreign currency market, hence their exposure to currency fluctuations could be different from non-financial firms. In addition, non-financial firms are highly exposed to the effect of exchange rate fluctuations as they are significantly involved in export-import businesses. As the study concentrates on Malaysian single market, FTSE Bursa Malaysia Kuala Lumpur Composite Index (FBM-KLCI) was used to represent the market index. With this regard, daily stock returns of the individual firms are decomposed using the Haar wavelet transformation technique into different orthogonal timescales. The transformed data are then regressed against the FBM-KLCI as the market index and the daily exchange value of USD/MYR. The results show different beta values for different timescales. This is supported by the similar result by [17].

Malaysia is selected due to the country's active involvement with international trade and ranked among the 20 top trading nations in the world [3]. The extensive trade activities in Malaysia is illustrated by the trade-to-GDP ratio (134\%) which signifies high degree of openness compared to developed countries such as the United States $(28 \%)$, the United Kingdom (56\%), and Japan (36\%). As the currency exposure in the Malaysian market is shown to be high by [3], further study on the level of currency exposure in the country is very much relevant to the research field. In addition, study involving advance measurement technique that enables the decomposition of the low and high trading frequencies will better accommodate the investors in a volatile market such as Malaysia.

\section{B. WAVELET ANALYSIS}

For each stock market, we collect daily return series (256 observations) for each stock in the sample as well as for the market index. Daily stock returns are calculated from stock price $(\mathrm{P})$ as follows, $r_{\mathrm{it}}=\ln \left(\frac{P_{\mathrm{it}}}{p_{\mathrm{it}-1}}\right)$ for stock $i$ at day $\mathrm{t}$

While the daily return on the market index and currency exchange are calculated as follows:

$$
\begin{gathered}
r_{\mathrm{mt}}=\ln \left(\frac{P_{\mathrm{it}}}{p_{\mathrm{it}-1}}\right) \\
r_{\text {USDt }}=\ln \left(\frac{\mathrm{USD_{t }}}{\mathrm{USD_{ \textrm {t } } - 1}}\right)
\end{gathered}
$$

After calculating the return series for every stock and for the market, the wavelet analysis is used to separate each of the return series into its constituent multiresolution (multihorizon) component. This is achieved by applying the discrete wavelet transformation (DWT) on daily return series through even-spaced point of time distribution across the sample period. The transformation enables decomposing the return series from time domain to scale domain which provides better understanding on the frequency of the activity occurrence. Data decomposition involves the following scale crystals (j): D1 (2-4 days), D2 (4-8 days), D3 (8-16 days), D4 (16-32 days), D5 (32-64 days), D6 (64-128 days), and D7 (128-256 days) using the orthogonal Haar wavelet transformation. The decomposition is conducted until D7 to denote the longest timescale in the study which is 256 days. This scale covers the standard 252 trading days in a year. The transformed return series $\mathrm{r}(\mathrm{t})$ represents a linear combination of wavelet functions as follows:

$$
\begin{aligned}
& r(t) \approx \sum_{k} s_{j k} \emptyset_{j, k}(t)+\sum_{k} d_{j, k} \varphi_{j k}(t)+ \\
& \sum_{k} d_{j-1, k} \varphi_{j-1, k}(t)+\cdots+\sum_{k} d_{1, k} \varphi_{1, k}(t)
\end{aligned}
$$

Where:

$j$ is the number of scale crystals (intervals or frequencies) $k$ is the number of coefficients in the specified component $\emptyset_{-}(j, k)(t)$ and $\varphi_{-}(j, k)(t)$ are the father and mother orthogonal wavelet pair that denote the following expression for $j=1$ to 7 , respectively

$$
\begin{aligned}
& \emptyset_{j, k}(t)=2^{-\frac{1}{2} \emptyset\left(\frac{t-2^{j}}{2^{j}}\right)} \\
& \varphi_{j, k}(t)=2^{-\frac{L}{2}} \varphi\left(\frac{t-2^{j} k}{2^{j}}\right)
\end{aligned}
$$

Father wavelet represents the low-frequency (smooth) parts of the series, while the high-frequency (detailed) parts of the series are represented by mother wavelet.

$$
s_{I, k} \approx \int \emptyset_{I, k}(t) f(t) d t
$$

$$
d_{J_{k}, k} \approx \int \varphi_{I_{k} k}(t) f(t) d t
$$

$s_{-}(j, k)$ are called the 'smooth' coefficients that represent the underlying smooth behaviour of the series. On the other hand, the $d_{-}(j, k)$ are called the 'detail' coefficients that represent the scale deviations from the smooth process. The 
levels of activities are theoretically different between the mother and father wavelet, with more information is contained in the mother wavelet.

Once the decomposed series for each series for each frequency is obtained, an OLS regression is run for each stock on each decomposed crystal of the market portfolio $R_{-} m^{\wedge} j$ and currency exchange $R_{-}(x)^{n_{j}}$ as per the following model by [5]:

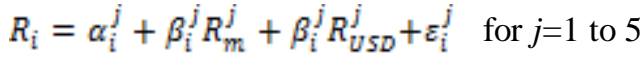

The coefficient $\beta_{-} i^{{ }^{\wedge} j}$ is the key variable we are trying to examine. If $\beta_{-} i^{\Lambda_{j}}$ is essentially similar across scales $j$, then the beta does not showcase any multiscale nature. Hence, the beta calculated using the daily return basically does not differ from the beta calculated using the weekly or monthly returns. However, if changes of $\beta_{-} i^{\Lambda_{j}}$ depend on the scale $j$, then the beta is deemed as possessing multiscale behaviour. With this, the return interval must be specifically chosen rather than the current arbitrary choice practice. Once the results are obtained, the model is then tested for heteroscedasticity issue by utilising the Breusch-Pagan test. Based on the equation (9), model suffering from heteroscedasticity will be re-run using the $\operatorname{GARCH}(1,1)$. $\operatorname{GARCH}(1,1)$ is used due to its ability to model the variance generating process in financial time series [11]. Equation (9) is also re-run using real interest rate fur robustness purpose which is included in the later section of the paper.

\section{RESULTS}

Table $\mathrm{i}$ shows the results of beta coefficient $\beta_{-} i^{\mathrm{A}}{ }^{j}$ and $R^{\AA_{2}}$ for each decomposed $j$ scale crystals of the market index $R_{-} m^{\Lambda_{j}}$ and currency exchange $D_{-} u s d^{\mathbb{A}_{j}}$. The mean, max, and min are shown for distribution of beta exposure for each scale $j$. As can be seen in Table 1, the beta coefficient for the selected non-financial firm in Malaysia show a multiscale tendency. This is illustrated by the non-monotonous change in the beta values across the time scales. Comparing the mean of D1 as the shortest interval with D7 as the longest interval, the mean value is higher for the low frequency horizon (high scale). The findings are relevant for the relation between risk and trading interval. [17] found similar findings and connoted the higher systematic risk faced by long-term investors compared to short-term investors.

Table i: Regression Results from the Decomposed Crystals of Individual Stock Return

\begin{tabular}{ccccccc}
\hline & Mean & Max & Min & $\mathbf{R}^{2}$ & Mean + & Mean - \\
\hline $\begin{array}{c}\text { Non-de } \\
\text { compos }\end{array}$ & -0.05 & 0.31 & -0.51 & 0.00 & 0.09 & -0.13 \\
ed & & & & & & \\
D1 & 0.28 & 0.79 & -0.51 & 0.01 & 0.29 & -0.26 \\
D2 & -0.37 & 0.14 & -1.49 & 0.06 & 0.11 & -0.39 \\
D3 & -0.32 & 0.30 & -1.43 & 0.03 & 0.12 & -0.37 \\
D4 & 0.08 & 0.78 & -0.52 & 0.14 & 0.22 & -0.19 \\
D5 & -0.07 & 0.56 & -1.01 & 0.22 & 0.27 & -0.31 \\
D6 & -0.39 & 0.55 & -1.83 & 0.29 & 0.23 & -0.64 \\
D7 & -0.34 & 0.79 & -1.78 & 0.45 & 0.24 & -0.60 \\
S7 & -0.63 & 2.07 & -1.89 & 0.43 & 0.49 & -0.90 \\
\hline
\end{tabular}

Interestingly, the mean of beta for all crystals are significantly higher than the beta value obtained without data decomposition. Similar trend is observed for the $R^{\Lambda_{2}}$ as lower value (0.0004) is obtained through the OLS regression compared to wavelet results (0.0052-0.4498). This indicates the market index and currency return are more capable to explain the individual stock return when the timescale nature of the time-series is taken into consideration.

In Table ii(a) and ii(b), the decomposed individual stock returns are regressed according to their respective industries. A few industries showcase the common findings where the mean of beta increases for bigger return interval, namely the travel and leisure, industrial engineering and transportation, oil and gas producers and equipment, industrial metals and mining, chemicals, automobile and parts, general retailer, household goods and home construction, technology hardware, software, equipment and services, and personal and leisure goods.

Table ii(a): Results of the Decomposed Crystals of Individual Stock Return According to Industry

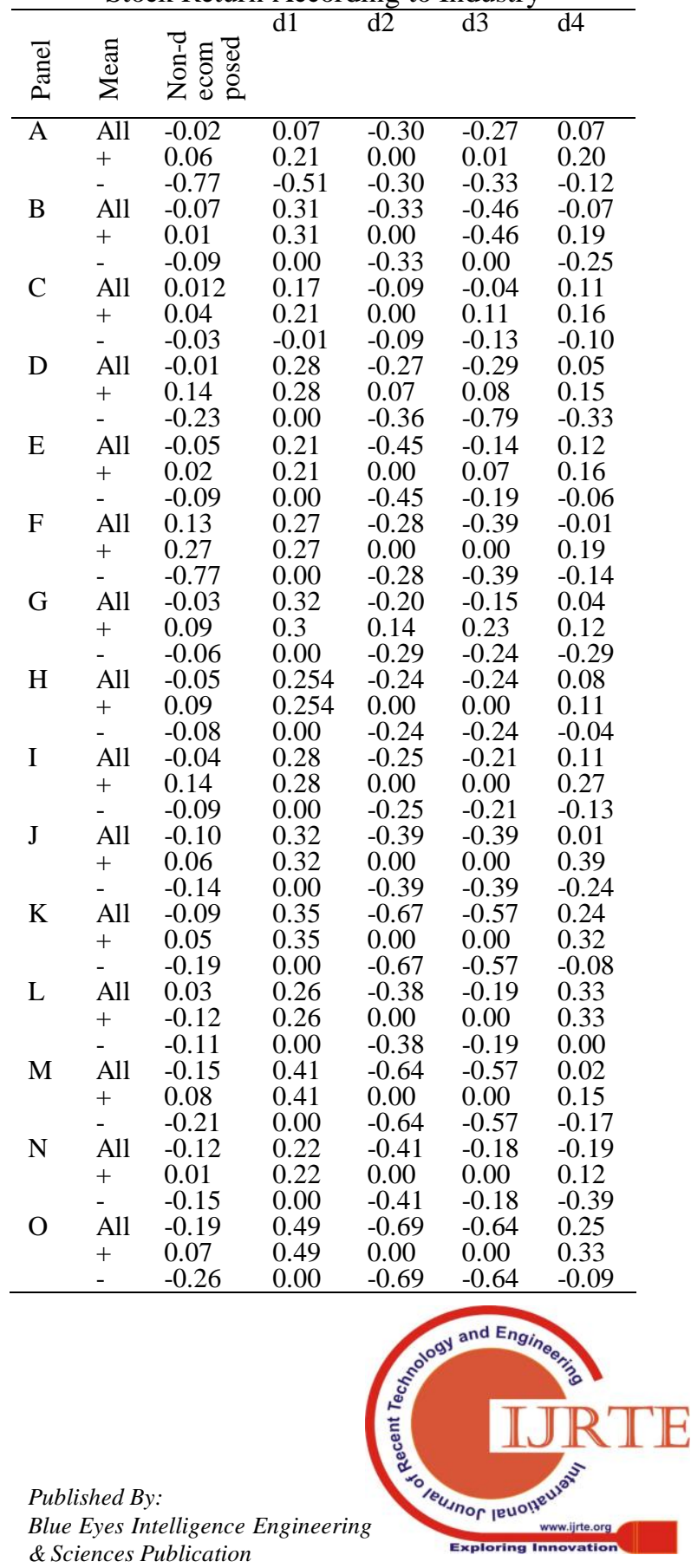


Table ii(b): Results of the Decomposed Crystals of Individual Stock Return According to Industry

\begin{tabular}{|c|c|c|c|c|c|}
\hline & & d5 & d6 & d7 & s7 \\
\hline 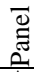 & $\sum^{\Xi}$ & & & & \\
\hline \multirow[t]{3}{*}{$\overline{\mathrm{A}}$} & All & 0.18 & -0.22 & 0.13 & 0.33 \\
\hline & + & 0.25 & 0.11 & 0.22 & 0.95 \\
\hline & - & -0.10 & -0.44 & -0.21 & -0.60 \\
\hline \multirow[t]{3}{*}{ B } & All & 0.04 & -0.63 & -0.48 & -0.28 \\
\hline & + & 0.32 & 0.07 & 0.00 & 0.13 \\
\hline & - & -0.15 & -0.79 & -0.48 & -0.38 \\
\hline \multirow[t]{3}{*}{$\mathrm{C}$} & All & -0.14 & 0.08 & 0.13 & -0.21 \\
\hline & + & 0.25 & 0.16 & 0.25 & 0.15 \\
\hline & - & -0.24 & -0.05 & -0.31 & -0.45 \\
\hline \multirow[t]{3}{*}{ D } & All & -0.02 & -0.46 & -0.78 & -0.53 \\
\hline & + & 0.21 & 0.16 & 0.19 & 0.21 \\
\hline & - & -0.37 & -0.88 & -1.02 & -1.02 \\
\hline \multirow[t]{3}{*}{ E } & All & 0.16 & -0.03 & 0.05 & -0.83 \\
\hline & + & 0.33 & 0.51 & 0.14 & 0.19 \\
\hline & - & -0.10 & -0.16 & -0.34 & -1.09 \\
\hline \multirow[t]{3}{*}{$\mathrm{F}$} & All & -0.35 & -0.48 & -0.65 & -0.74 \\
\hline & + & 0.00 & 0.05 & 0.00 & 0.00 \\
\hline & - & -0.35 & -0.52 & -0.65 & -0.74 \\
\hline \multirow[t]{3}{*}{ G } & All & -0.21 & -0.74 & -0.63 & -1.38 \\
\hline & + & 0.41 & 0.12 & 0.00 & 0.00 \\
\hline & - & -0.37 & -0.96 & -0.63 & -1.38 \\
\hline \multirow[t]{3}{*}{$\mathrm{H}$} & All & -0.02 & 0.03 & -0.49 & -0.81 \\
\hline & + & 0.05 & 0.27 & 0.00 & 0.06 \\
\hline & - & -0.14 & -0.94 & -0.49 & -1.03 \\
\hline \multirow[t]{3}{*}{ I } & All & 0.02 & -0.62 & -0.38 & -0.67 \\
\hline & + & 0.29 & 0.07 & 0.34 & 0.32 \\
\hline & - & -0.39 & -0.79 & -0.56 & -0.92 \\
\hline \multirow[t]{3}{*}{$\mathrm{J}$} & All & -0.24 & -0.59 & -0.46 & -0.77 \\
\hline & + & 0.18 & 0.00 & 0.05 & 0.00 \\
\hline & - & -0.34 & -0.59 & -0.59 & -0.77 \\
\hline \multirow[t]{3}{*}{ K } & All & -0.14 & -0.38 & -0.39 & -0.76 \\
\hline & + & 0.47 & 0.55 & 0.29 & 0.00 \\
\hline & - & -0.29 & -0.61 & -0.86 & -0.76 \\
\hline \multirow[t]{3}{*}{$\mathrm{L}$} & All & -0.09 & -0.70 & -0.67 & -0.28 \\
\hline & + & 0.27 & 0.32 & 0.00 & 2.07 \\
\hline & - & -0.34 & -0.960 & -0.67 & -0.87 \\
\hline \multirow[t]{3}{*}{ M } & All & -0.09 & -0.75 & -0.17 & -1.23 \\
\hline & + & 0.56 & 0.00 & 0.51 & 0.19 \\
\hline & - & -0.26 & -0.75 & -0.62 & -1.58 \\
\hline \multirow[t]{3}{*}{$\mathrm{N}$} & All & -0.13 & -0.09 & -0.37 & -0.22 \\
\hline & + & 0.22 & 0.42 & 0.42 & 0.73 \\
\hline & - & -0.64 & -0.42 & -0.57 & -0.46 \\
\hline \multirow[t]{3}{*}{$\mathrm{O}$} & All & -0.01 & -0.46 & -0.00 & -0.99 \\
\hline & + & 0.32 & 0.29 & 0.14 & 0.00 \\
\hline & - & -0.49 & -0.64 & -0.21 & -0.99 \\
\hline
\end{tabular}

Panel A represents travel and industry, Panel B for industrial engineering and transportation, Panel $\mathrm{C}$ for food and beverages producers, Panel D for oil and gas producers and equipment, Panel E for general industrial, Panel F for construction and materials, Panel $\mathrm{G}$ for industrial metals and mining, Panel $\mathrm{H}$ for chemicals, Panel I for automobile and parts, Part J for general retailer, Panel K for household goods and home construction, Panel L for technology hardware, software, equipment and services, Panel M for forestry and paper, Panel $\mathrm{N}$ for personal and leisure goods, and Panel $\mathrm{O}$ for electronic and electrical equipment.

Meanwhile, a few other industries show decreasing beta mean over bigger return interval. The decreasing beta values over longer interval may lie on two bases: the business nature and size of the firms. [18] asserted smaller estimated beta for wider interval for large firms. Interestingly, almost all industries show zero exposure level when tested for D2 and D3 crystals. With this regard, the Malaysian sample firms are found to be least exposed to exposure within these time intervals in opposed to the common practice of monthly investment strategy.

Conforming to the prediction, thirteen out of fifteen industries show increasing negative exposure towards larger return interval. This is in contrary to only five industries which show increasing trend for positive beta values, with these industries benefit from the currency fluctuations over longer time horizons. [31] denoted the different response to currency exposure as due to the varying export and import exposed nature of the industries. In general, the study concludes the overall exposure in this study showcase multiscale nature due to the non-monotonic change of exposure levels across the scales.

\section{V.ROBUSTNESS TEST}

Additional tests are conducted to examine the consistency of our results. The results are tested to be robust to the use of alternative exchange-rate index to estimate the firms' exposure. Instead of using nominal exchange rate, we resorted to the real exchange rate data. From Table 3, higher currency exposure is observed across the timescales. Higher mean beta for longer return interval negative is likewise to the findings of the base case study in Table 1. Consistent with previous analysis, mean of negative exposure follows the common higher negative exposure for longer scale (low frequencies). As real inflation level in emerging markets is more visible compared to developed countries [9], the findings sign the significant influence of inflation towards the firms' operations and returns.

Table iii: Robustness Results for the Decomposed Crystals of Individual Stock Return using the Real Exchange Rate

\begin{tabular}{llllll}
\hline & Mean & Max & Min & Mean + & Mean - \\
\hline D1 & 0.19 & 0.79 & -0.77 & 0.32 & -0.18 \\
D2 & -0.27 & 0.67 & -1.49 & 0.24 & -0.44 \\
D3 & -0.22 & 0.71 & -1.43 & 0.21 & -0.44 \\
D4 & -0.06 & 1.00 & -1.29 & 0.21 & -0.26 \\
D5 & -0.32 & 1.69 & -2.61 & 0.32 & -0.58 \\
D6 & -0.22 & 0.71 & -1.43 & 0.89 & -0.73 \\
D7 & 0.40 & 3.70 & -2.09 & 1.09 & -0.68 \\
S7 & 0.99 & 3.88 & -3.89 & 1.68 & -1.04 \\
\hline
\end{tabular}

\section{CONCLUSION}

The study analysed 75 non-financial Malaysian firms to examine the multiscale nature of currency exposure. The daily stock return from 1995 - 2016 are decomposed using the wavelet analysis. The decomposed stock returns are then run against the market index and currency exchange to estimate the exposure beta at different time scales. The study finds non-monotonic exposure throughout the scales, suggesting the existence of multiscale nature among the sample firms. The exposure measured at different time scales shows that exposure tends to be more concentrated at longer time interval (higher frequencies). Confirming to the conventional findings by [17], the results are regarded as plausible and exhibit strong policy implications.

Existence of multiscale tendency of the average beta coefficient is relevant considering the multi investment horizons in the market. These multi horizons characteristics arise from the different and varying trading strategies by investors and market participants which are more wide ranging in a volatile and illiquid market such as Malaysia. With this, results of this study manage to further accentuate the need for the investors to be 
more informed of the potential exposure arising from the varying multi investment horizons. Despite the regulations and restrictions by the government to improve the market efficiency, less and miss-informed investors would still cause problems such as illiquidity and high transaction cost. In this regard, measuring the exposure level in accordance to the multiscale domain must be imperatively introduced to the market wide investors in order to improve the efficiency and depth of the market. Further study could also be done to re-measure the multiscale exposure either from other similar market characteristic as comparison purpose or inclusion of other variables that potentially inflict the multiscale nature of the exposure.

\section{REFERENCES}

1. M. Adler, and B. Dumas, "Exposure to Currency Risk: Definition and Measurement", Financial Management 13(2), 41-50, 1984.

2. G. Allayannis, and E. Ofek, "Exchange Rate Exposure, Hedging, and the Use of Foreign Currency Derivatives", Journal of International Money and Finance 20, 273-296, 2001.

3. O. I. Bacha, A. Mohamad, S. R. S. M., Zain, and M. E. S. M. Rasid, "Foreign Exchange Exposure and Impact of Policy Switch - the Case of Malaysian Listed Firms", Applied Economics 45:20, 2974-2984, 2013.

4. D. C. Parsley, and H. A. Popper, "Exchange Rate Pegs and Exchange Rate Exposure in East and South East Asia", Journal of International Money and Finance 25, 992-1009, 2006.

5. P. Jorion,, "The Pricing of Exchange Rate in Stock Market", The Journal of Financial and Quantitative Analysis 26(3), 363-376, 1990.

6. W. H. Yip, and H. Nguyen, "Exchange Rate Exposure and the Use of Foreign Currency Derivatives in the Australian Resources Sector", Journal of Multinational Financial Management, 22, 151-167, 2012.

7. K. L. Dewenter, R. C. Higgins, and T. T. Simin, "Can Event Study Methods Solve the Currency Exposure Puzzle?", Pacific-Basin Finance Journal 13, 119-144, 2005.

8. E. F. Fama, and K. R. French, "The Cross-section of Expected Stock Returns", The Journal of Finance XL12, 2, 1992.

9. S. M. Bartram, and G. M. Bodnar, "The Exchange Rate Exposure Puzzle”, Managerial Finance 33(9), 642-666, 2007.

10. A. B. Dar, A. Shah, N. Bhanja, and A. Samantaraya, "The Relationship Between Stock Prices and Exchange Rates in Asian Markets", South Asian Journal of Global Business Research 3(2), 209-224, 2014.

11. A. Muller, and W. F. C. Verschoor, "Asian Foreign Exchange Risk Exposure", Journal of the Japanese and International Economies 21 , 16-37, 2007.

12. H. Abdul Wahab, M. A. Amir Husin, M. A., N. Mohd. Nordin, Y. S. Yusoff, and W. N. R. A, Zainudin, "Foreign Currency Exposure and Hedging Practices: New Evidence from Emerging Market of ASEAN-4", Advanced Science Letters 23(5), 4939-4943, 2017.

13. E. Clark, and S. Mefteh, "Asymmetric Foreign Currency Exposures and Derivatives Use: Evidence from France", Journal of International Management and Accounting 22:1, 2011.

14. H. Di Iorio, and R. Faff, "An Analysis of Asymmetry in Foreign Currency Exposure of the Australian Equities Market”, Journal of Multinational Financial Management 10, 103-159, 2002.

15. N. Elahi, F. Salimi, and E. Masoomzadeh, "Investigating Asymmetric Effects of Monetary Shocks on the Exchange Rate and Trade Balance, with an Emphasis on Inflation Targeting", Procedia Economics and Finance 36, 165-176, 2016

16. G. Koutmos, and A. D. Martin, "Asymmetric Exchange Rate Exposure: Theory and Evidence", Journal of International Money and Finance 22, 365-383, 2003.

17. M. Masih, M. Alzahrani, and O. Al-Titi, "Systematic Risk and Time Scales: New Evidence from an Application of Wavelet Approach to the Emerging Gulf Stock Markets", International Review of Financial Analysis 19, 10-18, 2010. Return Interval and Betas", Journal of Financial Economics 23, 79-100, 1989.

19. T. J. Brailsford, and A. J. Cusack, "A Comparison of Future Pricing Models in a New Market: The Case of Individual Share Futures", The Journal of Futures Markets 17(5), 515-541, 1997.

20. M. Gherman, R. Terebes, and M. Borda, "Time Series Analysis Using Wavelets and GJR-GARCH Models", $20^{\text {th }}$ European Signal Processing Conference (EUSIPCO 2012), 2012.
18. P. Handa, S. P. Kothari,and C. Wasley, "The Relation Between the

21. D. L. Donoho, "Nonlinear Solution of Linear Inverse Problem by Wavelet-Vaguelette Decomposition", Applied and Computational Harmonic Analysis 2, 101-126, 1995.

22. J. B. Ramsey, "The Contribution of Wavelets to the Analysis of Economic and Financial Data, Reprinted in Wavelets", In B. W. Silverman, \& J. C. Vassilicos (Eds.), Oxford: Oxford Univ. Press Chapter 12, 1999.

23. D. N. Gujarati, Basic Econometrics. Mc-Graw-Hill Higher Education, Singapore. $3^{\text {rd }}$ Edition, 2003.

24. B. Bjornson, H. S. Kim, and K. Lee, "Low and High Frequencies Macroeconomic Forces in Asset Pricing", Quarterly Review of Economics and Finance 39, 77-100, 1999.

25. M. Alzahrani, M. Masih, and O. Al-Titi, “ Linear and Non-linear Granger Causality Between Oil Spot and Future Prices: A Wavelet Based Test", Journal of International Money and Finance 48, 175-201, 2014.

26. R. Gencay, F. Selcuk, and B. Whitcher, "Differentiating Intraday Seasonalities Through Wavelet Multi-scaling”, Physics A 289, 543-556, 2001.

27. R. Gencay, F. Selcuk, and B. Whitcher, "Scaling Properties of Foreign Exchange Volatility", Physics A 289, 249-266, 2001.

28. J. Karuppiah, and C. A. Los, "Wavelet Multiresolution Analysis of High-frequency Asian FX Rates, Summer 1997”, International Review of Financial Analysis 14, 211-246, 2005.

29. J. B. Ramsey, and C. Lampart, "The Decomposition of Economic Relationships by Timescale Using Wavelets: Expenditure and Income", Studies in Nonlinear Dynamics and Econometrics 3(4), 23-42, 1998.

30. P. O. Junior, G. Tweneboah, and A. M. Adam, "Interdependence of Major Exchange Rates in Ghana: A Wavelet Coherence Analysis", Journal of African Business 20(3), 407-430, 2019.

31. M. Kohler, J. Manalo, and D. Perera, "Exchange Rate Movements and Economic Activity", Bulletin, March Quarter, 47-54. Reserve Bank of Australia, 2014.

\section{AUTHORS PROFILE}

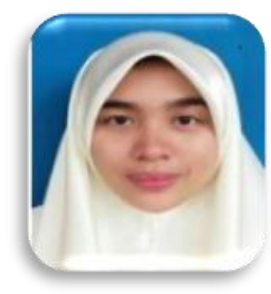

Wan Nurhanan Wan Suhaimi, is a Academic Fellow at the Faculty of Science and Technology (FST), Universiti Sains Islam Malaysia. She is currently pursuing her $\mathrm{PhD}$ in Financial Mathematics, specifying in the currency exposure. She obtained her Bachelor in Financial Mathematics from Universiti Sains Islam Malaysia in 2010. She later obtained her Master of Science in Financial Economy from Universiti Putra Malaysia in 2014.

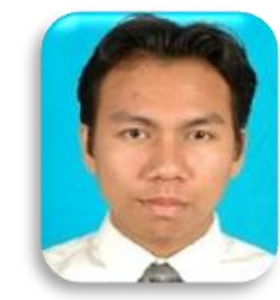

Dr. Hishamuddin Abdul Wahab, $\mathrm{PhD}$ currently serves as an academic at the Faculty of Science and Technology (FST), Universiti Sains Islam Malaysia. He received his first Bachelor with honours in Actuarial Science from Universiti Kebangsaan Malaysia in 2006. He gained his Master in Financial Mathematics from University of Wollongong, Australia in 2007. He obtained $\mathrm{PhD}$ in Islamic Finance from INCEIF (AACSB accredited) in 2013, with the research area in currency exposure. $\mathrm{He}$ is also a certified quantitative risk management (CQRM) awarded by IIPER, USA (AACSB member). Previously, he served several administration posts such as the head of Actuarial Science and Risk Management (ASRM) program under FST, USIM from 2014-2016 and the deputy director of Academic Quality and Accreditation division (AQAD) from 2017 -2018. His research mainly focuses on the empirical analysis in the area of banking, financial studies using statistical tools, and management practices among corporate institutions.

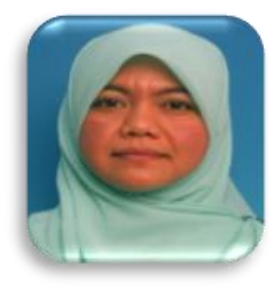

Dr. Rabihah Md. Sum, $\mathrm{PhD}$, is an academic at the Faculty of Science and Technology (FST) Universiti Sains Islam Malaysia. She obtained her first Bachelor in Actuarial Science from Universiti Kebangsaan Malaysia in 1999. She further obtained her Masters in Financial Management and Insurance from the Georgia State University in 2002. She obtained $\mathrm{PhD}$ in Actuarial Studies from the Macquarie University in 2015. She possesses high expertise in crisis and risk management fields, with numerous publications and supervision throughout her 12 years teaching experience. 